 \\ PROGRAMA DE INICIAÇÃO CIENTÍFICA
}

IVAN RODRIGUES DE AGUIAR

O EFEITO DA DENSIDADE DE NINHOS, CONSPICUIDADE DE OVOS E ESTRUTURA DA VEGETAÇÃO NA PREDAÇÃO DE NINHOS ARTIFICIAIS NO CERRADO

BRASÍLIA 


\section{Unल $U$ B \\ Centro Unıversitárıo de Brasílıa}

IVAN RODRIGUES DE AGUIAR

O EFEITO DA DENSIDADE DE NINHOS, CONSPICUIDADE DE OVOS E ESTRUTURA DA VEGETAÇÃO NA PREDAÇÃO DE NINHOS ARTIFICIAIS NO CERRADO

Relatório final de pesquisa de Iniciação Científica apresentado à Assessoria de Pós-Graduação e Pesquisa.

Orientação: Prof. Dr. Raphael Igor Dias

BRASÍLIA 


\title{
O EFEITO DA DENSIDADE DE NINHOS, COR DOS OVOS E ESTRUTURA DA VEGETAÇÃO NA PREDAÇÃO DE NINHOS NO CERRADO
}

\author{
Ivan Rodrigues de Aguiar - UniCEUB, PIBIC-CNPq, aluno bolsista \\ ivan.aguiar@sempreceub.com
}

\author{
Raphael Igor Dias - UniCEUB, professor orientador \\ raphael.dias@ceub.edu.br
}

A predação de ninhos é um evento ecológico que afeta diretamente o sucesso reprodutivo das aves. Dessa forma, durante a época reprodutiva, os progenitores investem em estratégias para maximizar o sucesso. Fatores como estrutura da vegetação, disponibilidade de recursos, tipo de substrato e abundância de predadores são avaliados na escolha do sítio de nidificação, aumentando assim a chance de sobrevivência do ninho. O objetivo do presente trabalho foi avaliar se a densidade de ninhos (maior ou menor), a coloração dos ovos (críptica ou conspícua) e a estrutura da vegetação (áreas campestres ou florestais) influenciam a taxa de predação de ninhos. Espera-se que os ninhos agregados em menor densidade, compostos por ovos de coloração críptica e localizados em áreas florestais apresentem taxas menores de predação. Ninhos artificiais foram posicionados em 64 transectos de $50 \mathrm{~m}$ de comprimento. Os ninhos foram dispostos no início (0 m), no meio $(25 \mathrm{~m})$ e no final $(50 \mathrm{~m})$ do transecto. Para simular o efeito de baixa densidade, foi alocado apenas um ninho por posição no transecto. Para o efeito de alta densidade foi utilizado um conjunto de três ninhos por posição no transecto, dispostos a uma distância de $5 \mathrm{~m}$ entre si. Cada ninho continha dois ovos, sendo um de codorna e outro de plasticina. Para investigar o efeito da coloração, os ovos foram pintados com tinta atóxica da cor marrom (críptica) e branca (conspícua). A altura dos ninhos foi padronizada em aproximadamente $1,5 \mathrm{~m}$. Todos os ninhos tiveram o mesmo tempo de exposição (7 dias). Nas análises, foi utilizado um modelo linear generalizado misto da família binomial, onde a situação final do ninho (predado ou não predado) foi a variável resposta e a densidade de ninhos, a coloração dos ovos e a estrutura da vegetação foram usadas como variáveis explicativas. A identificação do transecto foi usada como variável aleatória. Foram realizados testes de razão de verossimilhança para avaliar a influência de cada variável explicativa na probabilidade de predação de ninhos. Os ninhos distribuídos em áreas campestres, com coloração conspícua e em maior densidade demonstraram uma taxa superior de predação. Uma maior predação em áreas campestres pode ser explicada pelo dossel reduzido e, consequentemente, pela menor cobertura vegetal. Essa cobertura atua como obstáculo à detecção dos ninhos por predadores aéreos visualmente orientados como as aves, que são tidas como os principais predadores de ninhos no Cerrado. O agrupamento de ninhos no habitat pode facilitar a localização dos mesmos por predadores, pois eles podem investir em buscas adicionais em áreas próximas a ninhos encontrados. Esse comportamento adaptativo de forrageio pode aumentar os riscos de predação nas áreas de agregação. Por fim, a maior predação de ovos conspícuos pode estar associada a uma maior detectabilidade por predadores, principalmente os que possuem hábitos diurnos.

\footnotetext{
Palavras-Chave: Coloração críptica. Conspicuidade. Predador. Reprodução. Seleção de habitat.
} 
SUMÁRIO

1 INTRODUÇÃO

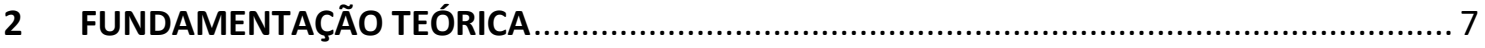

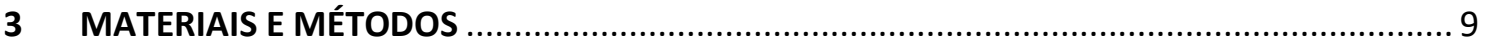

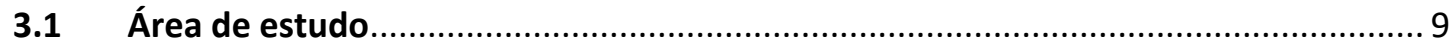

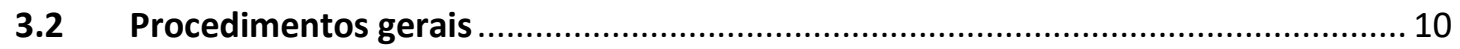

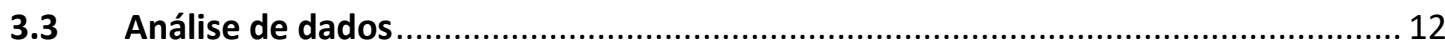

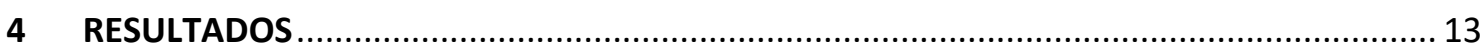

5 DISCUSSÃO

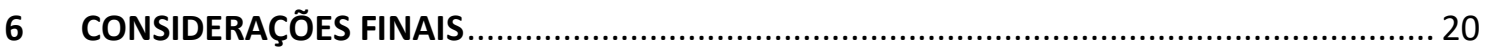

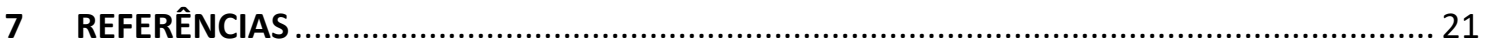




\section{INTRODUÇÃO}

A predação de ninhos é a principal causa do insucesso reprodutivo nas aves (RICKLEFS, 1969). Estudos têm demonstrado que as aves de zonas tropicais sofrem com indicies altíssimos de predação, alcançando números acima de $80 \%$, sendo que em regiões temperadas possuem uma taxa de predação bem inferior, variando de 40 a $60 \%$ (STUTCHBURY; MORTON, 2001).

Diante desse cenário, muitos aspectos comportamentais das aves que envolvem nidificação, parecem ser adaptações para se evitar a predação dos ninhos (FU et al., 2016). Dificultar ao máximo a vida do predador é um desafio universal para a maioria das aves. Assim, a seleção natural acabou favorecendo aqueles indivíduos que possuíam estratégias e defesas anti-predatórias mais vantajosas (MAINWARING et al., 2014). Contrariamente ao pressuposto que havia nenhuma ou pouca flexibilidade no comportamento de nidificação, hoje em dia existem evidências mostrando que as aves modificam seu comportamento a partir de suas experiências de sucesso e fracasso (DEEMING; REYNOLDS, 2015).

Durante a fase reprodutiva, as aves buscam observar e selecionar as melhores áreas, visando garantir condições ótimas para conseguir nidificar com sucesso, pois nessa época a demanda energética é fundamental para incubar com êxito (CONWAY; MARTIN, 2000; HAFTORN; REINERTSEN, 1985). Fatores como qualidade, quantidade e competição por recursos (BAASCH et al., 2017), densidade de predadores, tipo de vegetação (JAMES; WAMER, 1982), cor do substrato e dos ovos (STEVENS et al., 2017), acabam sendo fundamentais para aumentar seu valor adaptativo.

O objetivo do presente estudo foi investigar os fatores relacionados a predação de ninhos no Cerrado. Para isso, foram utilizados ninhos artificiais para testar as seguintes hipóteses: 1) ninhos em áreas campestres são mais predados que os localizados em áreas florestais, possivelmente devido a uma menor densidade de cobertura vegetal que influencia a ocultação do ninho; 2) ninhos compostos por ovos conspícuos têm uma taxa de predação mais elevada devido a maior facilidade de visualização dos mesmos; e 3) ninhos alocados em alta densidade apresentam maiores taxas de predação, uma vez que a agregação de recursos tende a facilitar o encontro dos mesmos por predadores. 


\section{FUNDAMENTAÇÃO TEÓRICA}

A heterogeneidade fitofisionômica do Cerrado é fundamental para a disposição e manutenção das comunidades, já que o meio favorece diversas possibilidades de nichos ecológicos, atendendo melhor a comunidade faunística em relação as suas necessidades, que envolvem recursos para forrageamento e nidificação. No caso das aves, esses fatores são extremamente importantes, pois a estrutura da vegetação é determinante para a escolha do substrato utilizado para a construção dos ninhos (JONER; RIBEIRO, 2009).

As características da estrutura da vegetação estão associadas a uma maior sobrevivência do conteúdo dos ninhos localizados no sítio reprodutivo. Um estudo envolvendo Passeriformes da América do Norte, entre eles Spizella pallida, constatou que regiões com diferentes tipos de gramíneas influenciam a densidade de aves nas áreas e demonstrou que quanto maior a cobertura vegetal próximo aos ninhos, maior é a sua sobrevivência (WINTER; JOHNSON; SHAFFER, 2005).

Aliado a isso, as tomadas de decisão dos indivíduos adultos, junto à sua experiência e competência irão contribuir para seu sucesso ou insucesso. Antes de se estabelecer em um local e começar a construir seu ninho, as aves procuram fazer uma análise do local escolhido para a nidificação, no qual serão avaliadas diversas variáveis, como a disponibilidade de materiais para a construção dos ninhos, o local onde o ninho ficará apoiado, se há quantidade de alimento disponível suficiente para o período de construção, incubação e após o nascimento do ninhego e sobre a densidade de predadores no local (HANSELL, 2000).

O comportamento de forrageamento dos predadores normalmente é induzido por estímulos sensoriais. Algumas pistas são deixadas nos ninhos pelas aves ou pelos próprios filhotes recém-nascidos, o que favorece mamíferos e répteis, que possuem uma melhor capacidade na detecção de odores e pistas químicas. Por outro lado, as aves são mais beneficiadas por meio do estímulo visual, principalmente durante seu voo (BRENNAN, 2010).

A predação de ovos traz abundantes recursos nutricionais para os diversos grupos de predadores, já que os ovos possuem em sua composição altos níveis de vitaminas, água, proteínas e minerais (HUNTON, 2005; MURPHY, 2010). Além da predação para consumação dos ovos e do ninhego, alguns casos são motivados para eliminar a competição por recursos no local, como descrito por Lindell (1996), em que espécies de aves, como o pardal-doméstico 
(Passer domesticus) e estorninho-comum (Sturnus vulgaris) se apropriam de ninhos de cavidades escavados por aves da família Picidae e Furnarridae.

Fatores relacionados à biologia reprodutiva de animais podem fazer com que se tornem predadores de ovos mais vorazes durante a época reprodutiva, como as fêmeas de esquilo-vermelho-americano (Tamiasciurus hudsonicus) quando estão grávidas, e que requerem uma boa quantidade de nutrientes para gerar energia suficiente para lactação (STEELE, 1998).

Em consequência de uma grande pressão causada pelos predadores de ninhos, as aves desenvolveram ao longo da evolução algumas estratégias anti-predatórias. Espécies que nidificam no solo e não utilizam nenhum tipo de ninho ou cobertura para esconder os ovos, usualmente apresentam uma coloração críptica dos ovos, dificultando o avistamento por predadores (BRENNAN, 2010).

Dessa forma, o ovo acaba sendo um dos estágios de vida mais preocupantes para qualquer ave, onde as defesas oferecidas aos ovos incluem uma boa camuflagem natural e defesa parental. Ainda assim, diversas espécies apresentam casca de ovo conspícua, o que parece ser contraditório, no sentido de se evitar chamar atenção de predadores para o ninho (HANLEY et al., 2013). Existem algumas espécies de aves, como Tinamus major, que incubam seus ovos em solo exposto e mesmo assim possuem coloração conspícua, o que sugere que a cor dos ovos pode ter outras utilidades além da funcionalidade de camuflagem (STODDARD; MARSHALL; KILNER, 2011) como regulação térmica, trocas gasosas ou até mesmo seleção sexual (CASTILLA et al., 2007).

Quando o ovo possui características semelhantes ao substrato, como tamanho e formato, essa combinação acaba afetando a capacidade do predador localizar os ovos (ENDLER, 1978). Solís e Lope (1995), observando um Charadriforme, Burhinus oedicnemis, chegaram à conclusão que os ovos depositados em áreas com maior semelhança do substrato conseguiram obter um maior sucesso reprodutivo.

Além da coloração dos ovos e a importância do substrato, estudos sugerem que a altura do ninho em relação ao solo influencia diretamente a taxa de predação, ou seja, quanto mais alto o ninho for disposto, maior seu sucesso reprodutivo. Porém, o posicionamento pode facilitar o avistamento realizado por aves durante seu voo. Os ninhos posicionados mais próximos ao chão ou com menor cobertura vegetal, por outro lado, ficam mais expostos a predação, principalmente por mamíferos e répteis (ALVAREZ; GALETTI, 2007). 
Weidinger (2002) encontrou evidências mostrando que áreas com alta agregação de ninhos pode refletir em maior atratividade para potenciais predadores devido à alta disponibilidade de alimentos em uma área reduzida, porém esse risco pode ser minimizado por meio de comportamentos de defesa dos ninhos e filhotes.

Optar por utilizar ninhos artificiais em experimentos permite investigar o papel de diversas variáveis ambientais, controlando, ao mesmo tempo, diferentes fatores como a densidade, o tipo da vegetação, a distribuição e altura dos ninhos, cor e tamanho dos ovos, tempo de exposição, dentre outros (RODRIGUEZ, 2004).

\section{MATERIAIS E MÉTODOS}

\section{1 Área de estudo}

O Cerrado possui diferentes composições fitofisionômicas, incluindo regiões florestais, savânicas e campestres. As regiões florestais basicamente se compõem de árvores de maior estatura e com dossel mais fechado, incluindo mata ciliar, mata de galeria, mata seca e cerradão. O ambiente savânico inclui árvores e arbustos dispostos em regiões gramíneas onde não há estrutura continua de dossel, sendo representadas por cerrado denso, ralo e vereda. Ambientes campestres possuem predominância de espécies herbáceas e arbustivas, englobando campo sujo, limpo e rupestre (CARDOSO DA SILVA; BATES, 2002; RIBEIRO et al., 1983; RIBEIRO; J. F.; WALTER, 1998)

O clima do bioma é bem definido, sendo considerado sazonal. O período chuvoso normalmente ocorre entre o mês de outubro a março, enquanto o período seco vai de abril a setembro, com temperaturas médias oscilando entre $22^{\circ}$ e $27^{\circ}$. A precipitação anual varia de acordo com a região, oscilando de 600 a $800 \mathrm{~mm}$ no limite com a Caatinga e chegando a 2.200mm em áreas próximas a Amazônia (JEPSON, 2005; KLINK; MACHADO, 2005; SCARIOT; SOUSA-SILVA; FELFILI, 2005)

Devido à grande disponibilidade de áreas campestres e florestais, o local escolhido para a realização do trabalho foi a Reserva Ecológica do IBGE (Figura 1). Também conhecida como Reserva Ecológica do Roncador (RECOR), é uma área de proteção de 1.350 ha. e está localizada no km 0 da BR 251, a uma distância média de $35 \mathrm{~km}$ do centro de Brasília. Precisamente, a entrada da Reserva do IBGE localiza-se nas coordenadas 15056'41"S e 47053'07'W (IBGE, 
2015). A RECOR foi considerada pela UNESCO, em 1993, como uma das Áreas Núcleo da Reserva da Biosfera do Cerrado (CÂMARA, 2008).

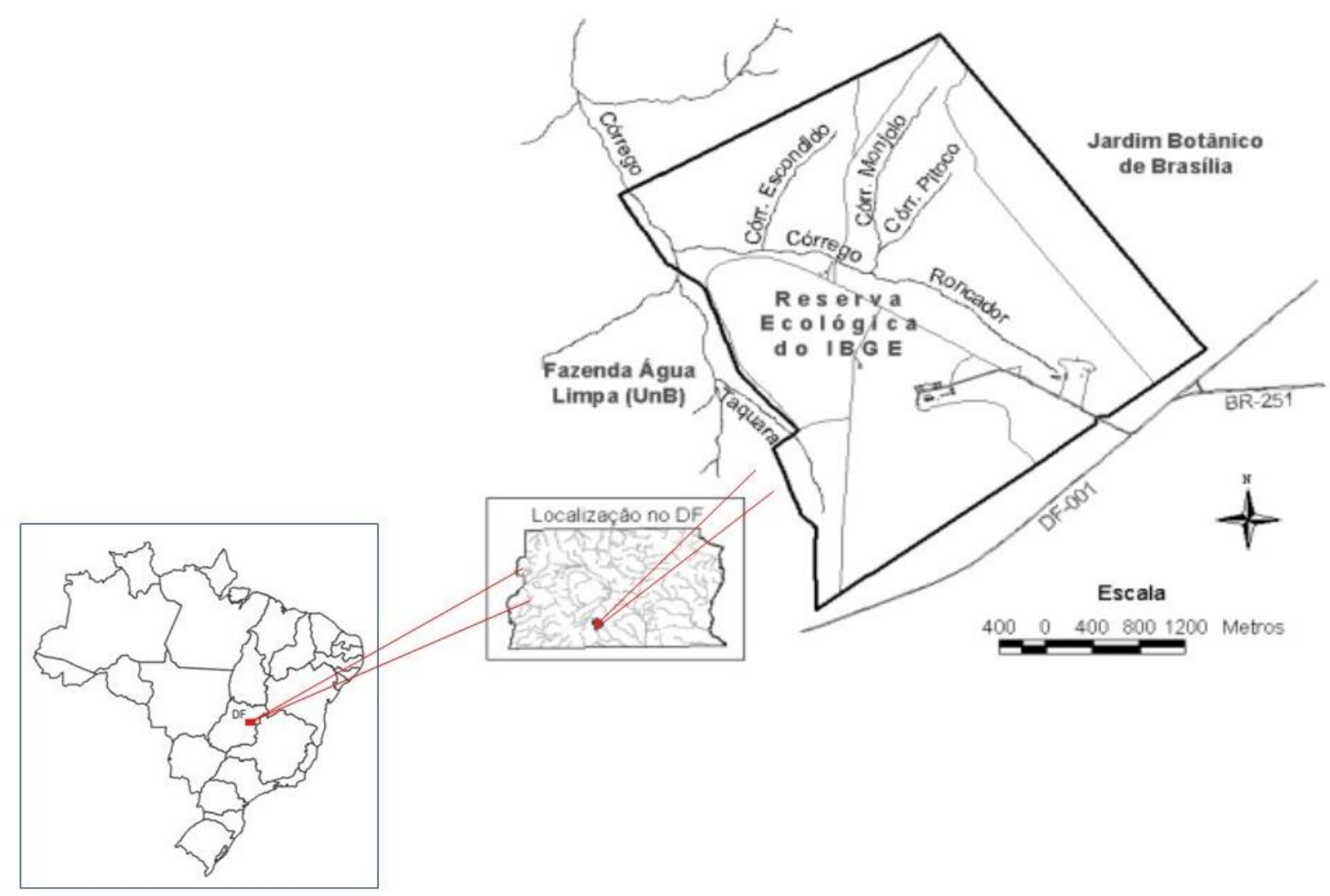

Figura 1 - Localização da área de estudo.

Fonte: IBGE, Diretoria de Geociências, Gerência do Centro de Estudos Ambientais do Cerrado.

\subsection{Procedimentos gerais}

Em cada expedição foram distribuídos um total de 48 ninhos artificias, dispostos em oito transectos. Ao longo de todo trabalho, foram alocados um montante de 384 ninhos em 64 transectos, totalizando oito saídas a campo. Os ninhos foram confeccionados a partir de fibra de sisal desfiado e montados com o intuito de simular ninhos naturais de Passeriformes. Os ninhos foram padronizados seguindo os valores médios de profundidade $(50 \mathrm{~mm})$ e diâmetro $(70 \mathrm{~mm})$ de espécies silvestres recorrentes nas fitofisionomias escolhidas (MARINI et al., 2009).

A altura dos ninhos em relação ao solo foi padronizada, sendo estabelecida uma altura média de 1,5m. Dessa forma, os ninhos foram dispostos na vegetação disponível na área que 
possua o perfil adequado. Durante todo o processo de montagem e, principalmente, na manipulação dos ninhos em campo, foram utilizadas botas e luvas para reduzir o efeito do odor humano (PADILHA, 2009).

Os ninhos foram organizados em transectos de 50 metros de comprimento e simularam áreas de baixa e alta densidade reprodutiva. Os transectos de baixa densidade tiveram um ninho disposto a cada 25 metros, totalizando três ninhos por transecto. Por outro lado, o transecto de alta densidade foi composto por conjuntos de três ninhos, começando no início $(0 \mathrm{~m})$, no meio $(25 \mathrm{~m})$ e no final $(50 \mathrm{~m})$, totalizando nove ninhos nesse tratamento. Os ninhos no tratamento de alta densidade tinham em média cinco metros de distância entre si (Figura 2).

\section{Alta densidade}

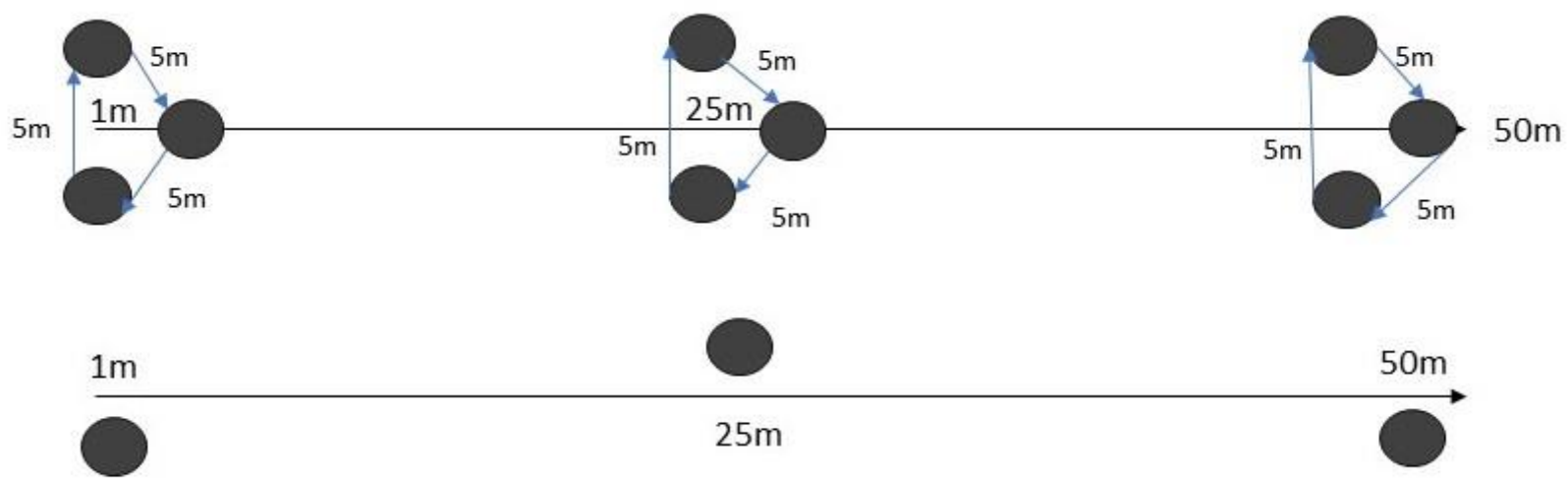

Baixa densidade

Figura 2 - Disposição dos ninhos em transectos de alta e baixa densidade.

A cada expedição foram demarcados quatro transectos em áreas florestais e quatro em áreas abertas. Para as áreas florestais, foram escolhidas fitofisionomias com um dossel fechado, englobando cerradão, mata seca, mata de galeria e mata ciliar. Já para as áreas abertas, foram selecionadas zonas de campo-sujo, cerrado stricto sensu ralo e campo cerrado.

Em cada fitofisionomia, metade dos transectos recebeu o tratamento de baixa densidade e a outra metade de alta densidade. Considerando os tratamentos de densidade, um transecto foi composto por ninhos com ovos crípticos e o outro com ovos conspícuos. Em cada ninho foi utilizado um ovo de codorna e um ovo de plasticina. Para controlar os efeitos da coloração, os ovos crípticos foram pintados com tinta atóxica na coloração marrom, por outro lado, os ovos conspícuos foram pintados na coloração branca. 
Os ninhos permaneceram expostos por sete dias e, ao final do período de exposição, serão registrados sinais de predação e forma de consumo dos ovos (e.g. se foram completamente ou parcialmente removidos). Foram considerados predados os ovos que desapareceram ou que registraram marcas de garras, bicadas, dentes ou arranhões (ALVAREZ; GALETTI, 2007).

A identificação dos possíveis predadores de ninhos artificiais foi realizada através de vestígios deixados pelos animais no momento da predação. Segundo o trabalho de França e Marini (2009), os maiores predadores de ovos de ninhos no Cerrado são justamente as outras aves. As marcas nos ovos que formam um "V" são consideradas vestígios deixados por aves e as outras mordidas podem ser comparadas com dados da literatura ou de exemplares disponíveis em coleções zoológicas (FULTON, 2017). Alguns ovos não foram passiveis de identificação devido ao nível de destruição.

Para auxiliar na identificação dos predadores, posicionamos uma armadilha digital fotográfica do modelo HC-550 M/G, 16 megapixels, para monitorar os ninhos artificiais em áreas campestres e florestais. O registro foi feito durante sete semanas, entre dezembro de 2017 até agosto de 2018, totalizando 49 dias da câmera em campo e gerando um esforço amostral total de aproximadamente 1176 horas de monitoramento dos ninhos.

\subsection{Análise de dados}

A probabilidade de predação foi investigada a partir dos registros das variáveis fixas. Para isso, foram ajustados modelos logísticos onde a situação final do ninho (predado ou não predado) foi a variável resposta e a densidade e a coloração foram as variáveis explicativas. As análises estatísticas foram desenvolvidas no software $R$ versão 3.3.3. Foi utilizado um modelo linear generalizado misto da família binomial (GLMM) para analisar o efeito da coloração dos ovos, densidade de ninhos e fitofisionomia na taxa de predação dos ninhos. Para isso, aplicou-se testes de razão de verossimilhança para verificar a influência e o efeito de cada variável explicativa na predação de ninhos. Inicialmente foram excluídas as interações mais complexas e depois foi verificada uma variável por vez. Utilizou-se o modelo completo e a partir dele, foram removidas as demais variáveis sucessivamente, onde foi analisado o efeito individual de cada variável. Também foi aplicado um qui-quadrado de independência, para 
verificar a maior prevalência de predação de mamíferos ou de aves nas duas fitofisionomias estudadas.

\section{RESULTADOS}

O experimento teve um esforço amostral total de 1,334 horas. Foi obtido um total de $29,9 \%(n=115)$ ninhos predados. Analisando os dois tipos de ovos que foram expostos, a plasticina sofreu predação em $40,8 \%$ dos ninhos ( $n=47)$. Já o ovo de codorna sofreu uma predação em $23,4 \%$ dos ninhos $(n=27)$ e a predação dos dois ovos no mesmo ninho foi observada em $35,6 \%$ dos casos $(n=41)$. Do total de ovos de plasticina predados, 55 deixaram marcas que possibilitaram a identificação do tipo de predador. Dos ovos marcados pelos predadores, 21 foram coletados em áreas florestais e 34 em áreas campestres.

A partir das marcas deixadas nos ovos pelos predadores, principalmente nos ovos de plasticina, conseguimos classificá-los em mamíferos e aves. Em áreas florestais, observamos uma predominância de mamíferos na predação $(n=15)$ e uma predação inferior de aves $(n=6)$. Em áreas de campo aberto, constatamos uma predação mais equilibrada, mamíferos representando $(n=5)$ e aves $(n=29)$. Percebeu-se uma associação estatística entre o ambiente e o tipo de predador, em áreas florestais observou-se uma maior prevalência de mamíferos, já nas áreas campestres notou-se uma predação superior causada por aves $\left(\chi^{2}=18.05 ; \mathrm{P}<\right.$ $0,001)$.

De acordo com as evidências encontradas nos ovos predados, principalmente as marcas deixadas nos ovos de plasticina. Entre os mamíferos, conseguimos identificar com clareza apenas marcas deixadas por animais da ordem Rodentia (Figura 3), devido aos dois dentes incisivos bem característicos (ZELDITCH et al., 2008) .

As imagens de potenciais predadores registradas pela armadilha fotográfica indicaram a presença de: Callithrix penicillata (Figura 4), Dasyprocta sp. (Figura 5), Sapajus libidinosus (Figura 6), Cryptonanus sp. (Figura 7) e Cyanocorax cristatellus (Figura 8). 


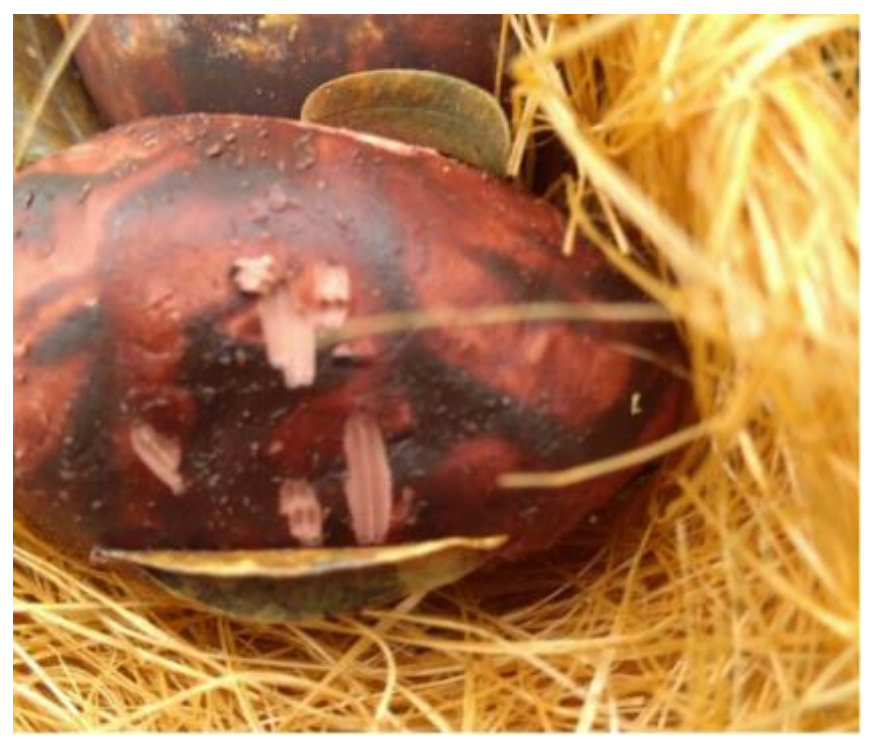

Figura 3 - Marcas de incisivos evidenciam predação por mamíferos roedores (ordem Rodentia).

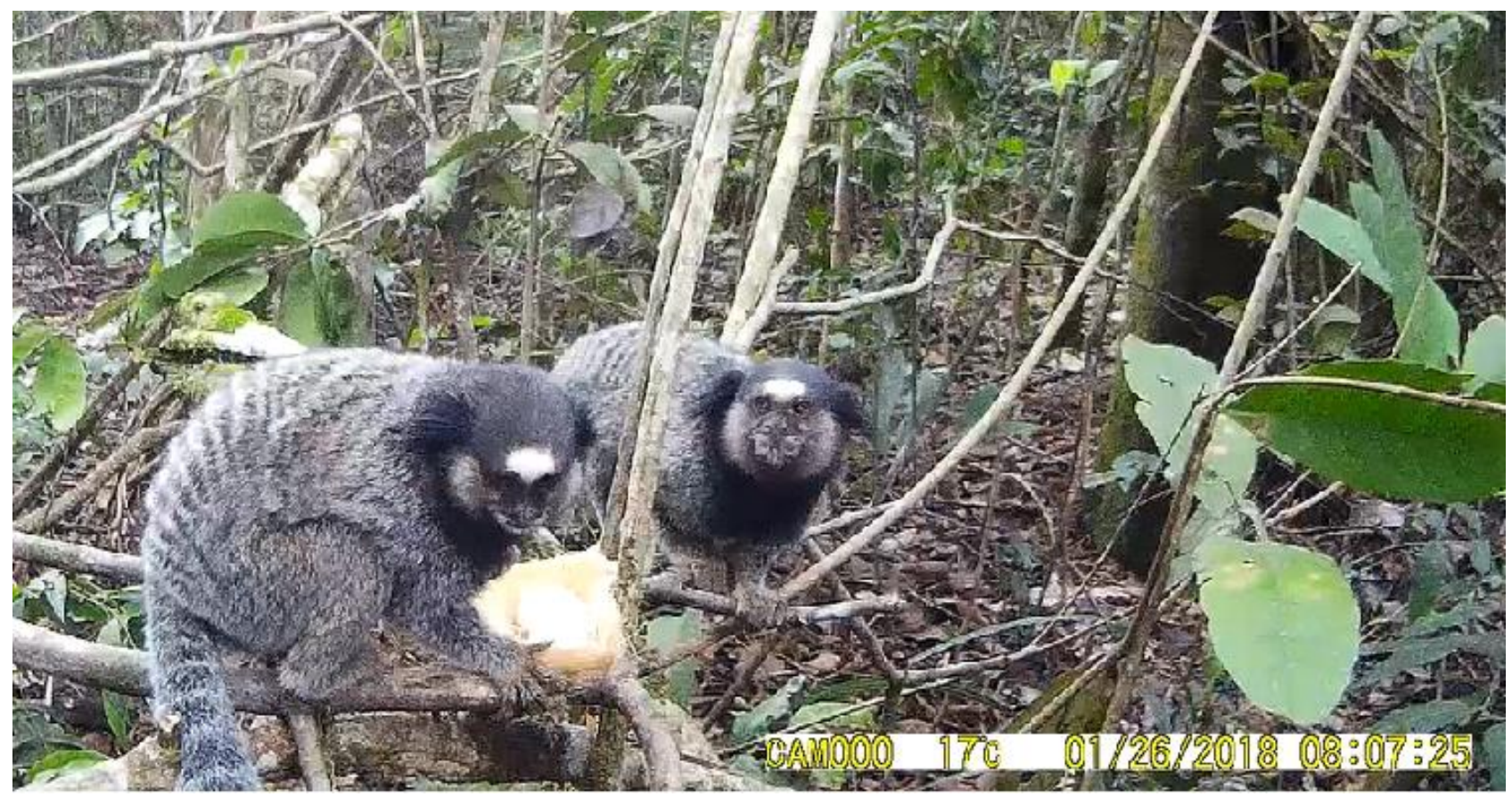

Figura 4 - Predação de ninhos por Callithrix penicillata. 


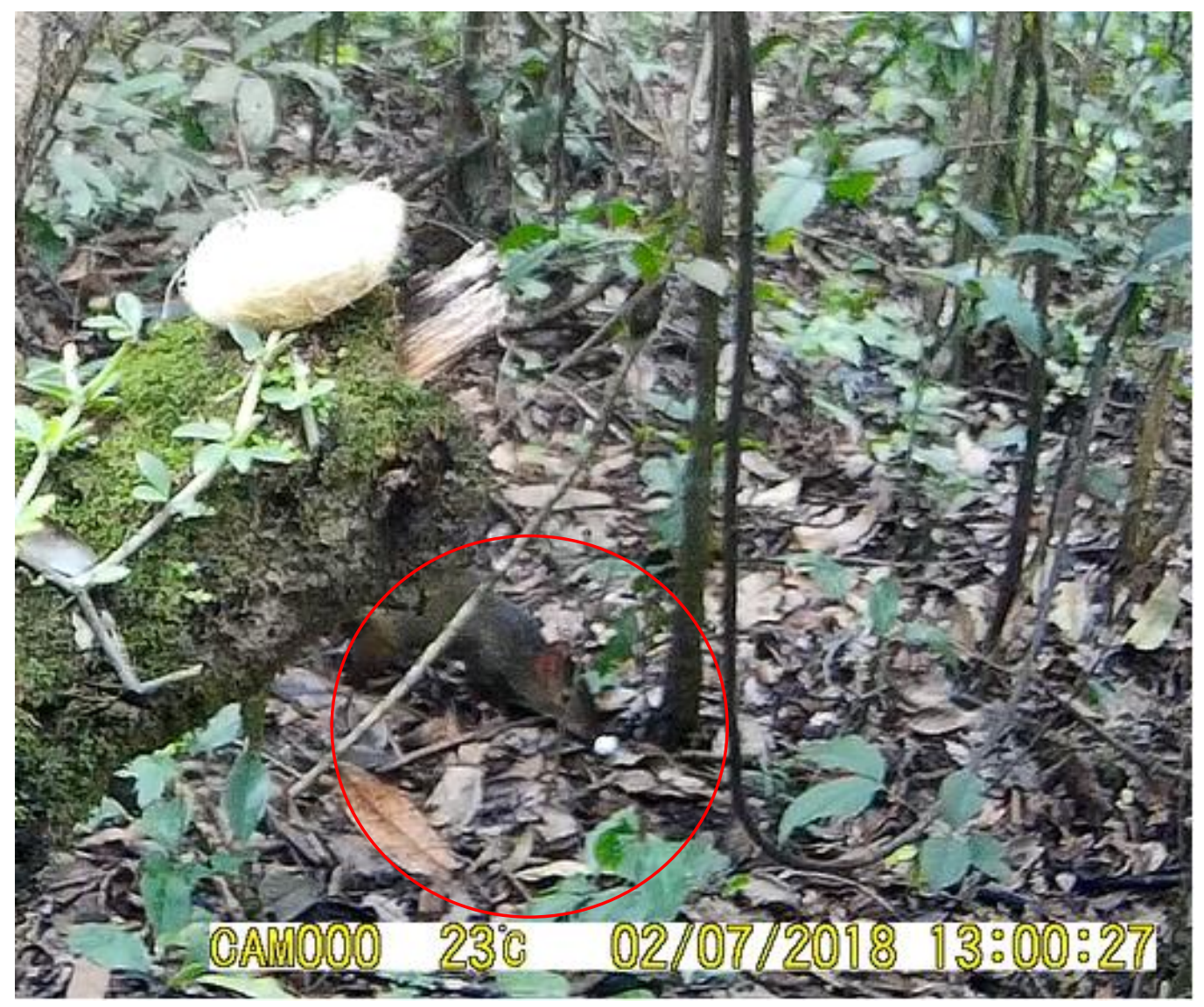

Figura 5 - Predação de ninhos por Dasyprocta sp.

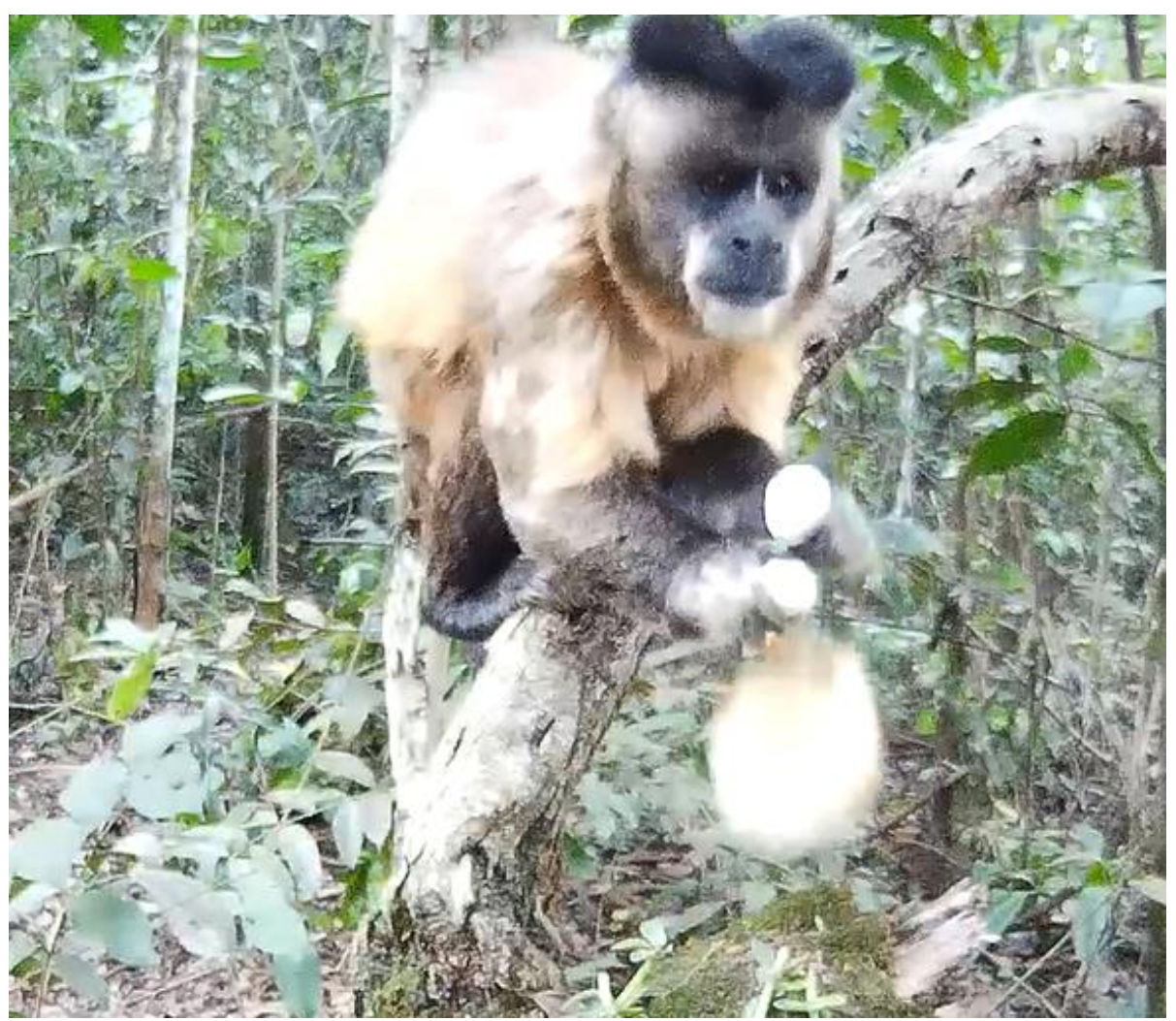

Figura 6 - Predação de ninhos por Sapajus libidinosus. 


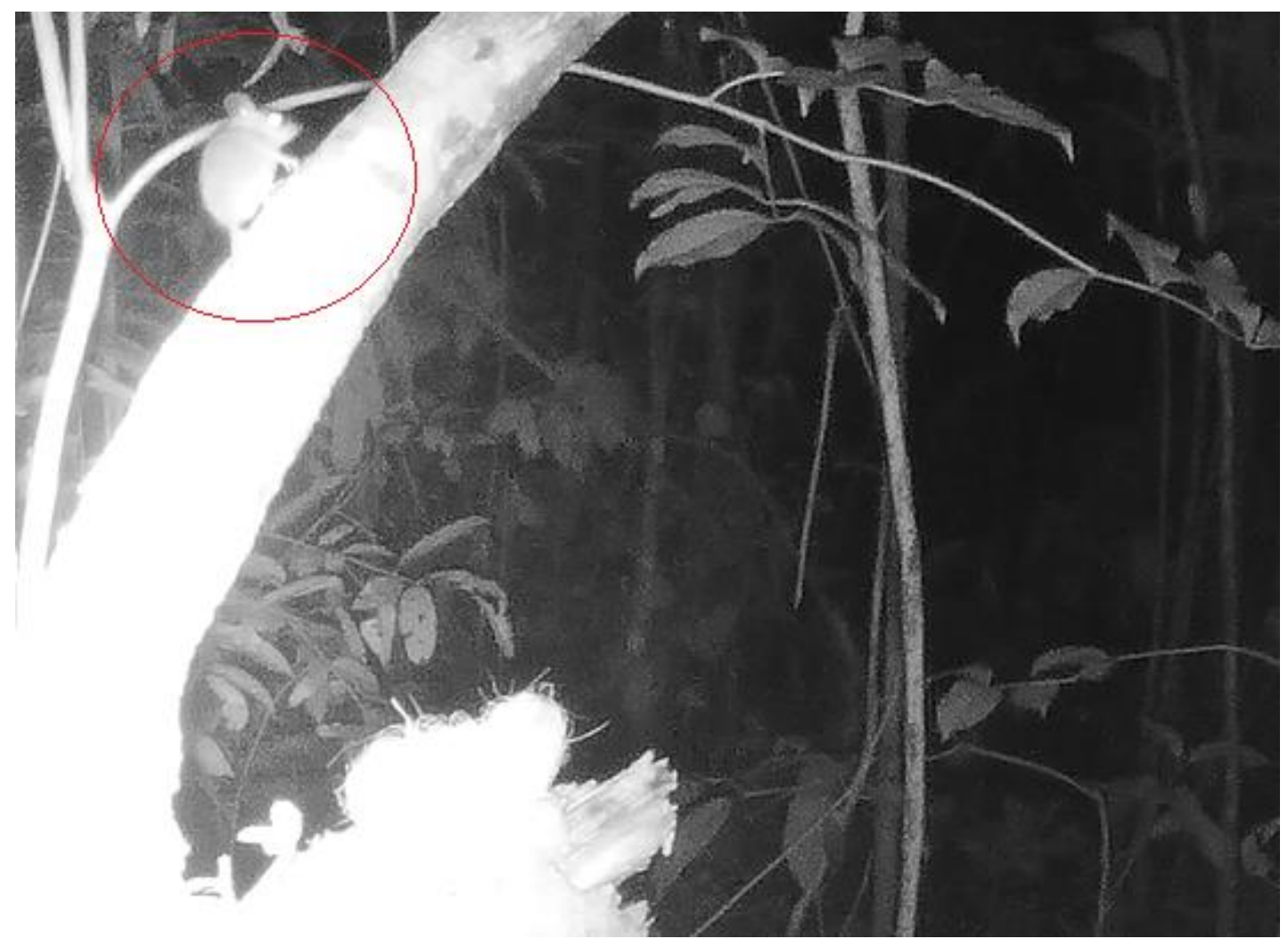

Figura 7 - Cryptonanus sp. rondando o ninho já predado.

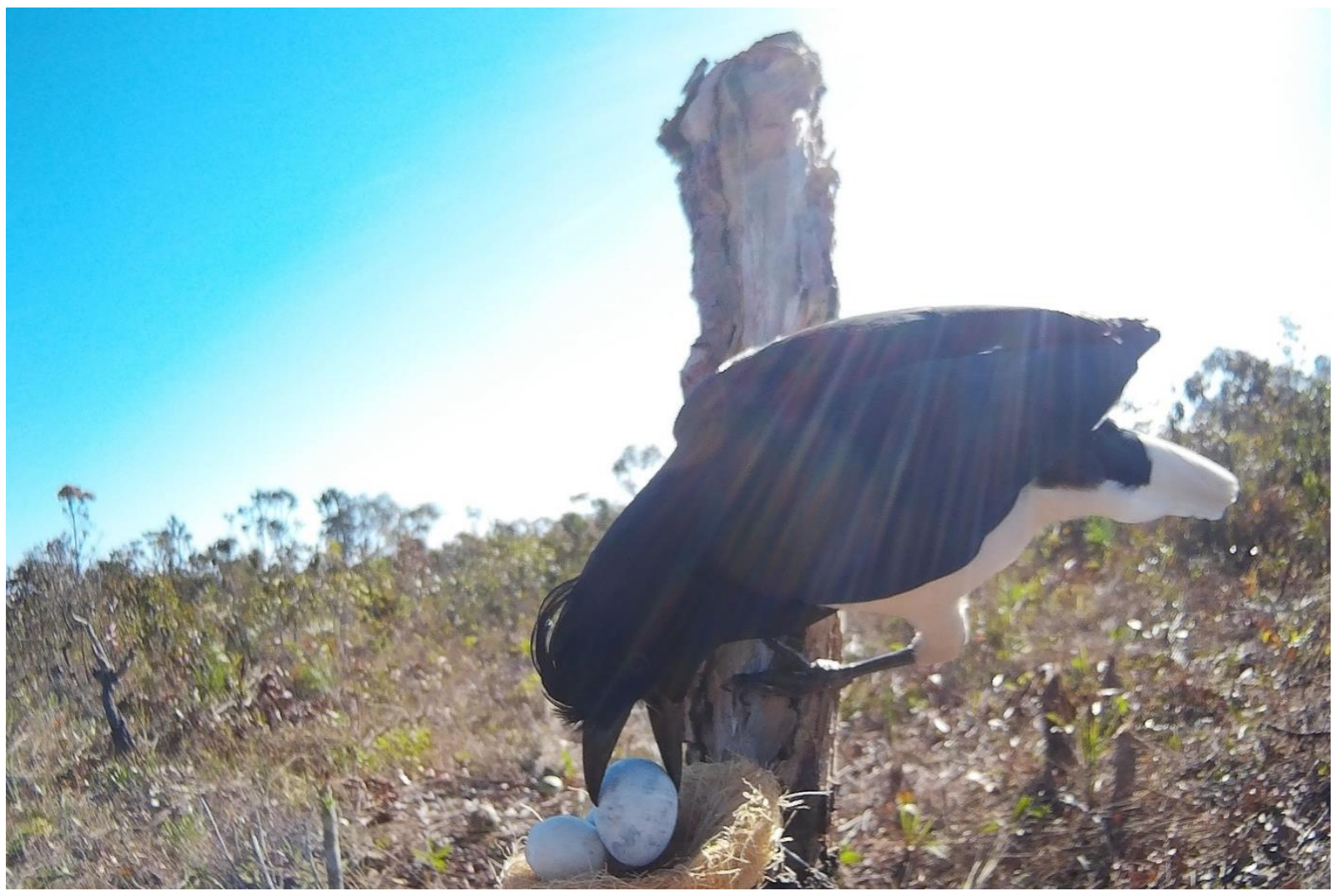

Figura 8 - Predação de ninhos por Cyanocorax cristatellus 
De forma geral, encontramos uma taxa de predação de ninhos superior em áreas campestres $63,4 \%(n=73)$ do que em áreas florestais $36,5 \%(n=42)$. 0 tipo de fitofisionomia influenciou significativamente a probabilidade de predação, demonstrando que áreas florestais são menos predadas que áreas campestres $\left(\chi^{2}=6,422 ; P<0,011\right)$.

A coloração dos ovos afetou significativamente a probabilidade de predação, sugerindo que ovos de coloração conspícua aumentam a chance do ninho ser localizado por potenciais predadores $\left(\chi^{2}=5,350 ; P<0,020\right)$.

Adicionalmente, o efeito de densidade dos ninhos também aumentou a probabilidade de predação, indicando que as taxas de predação de ninhos alocados em alta densidade são maiores que os distribuídos em baixa densidade $\left(\chi^{2}=4,243 ; P<0,039\right)$.

\section{DISCUSSÃO}

No Cerrado, os diferentes gradientes fitofisionômicos (RIBEIRO et al., 1983) proporcionam diversos recursos e opções para que as aves consigam encontrar um sítio de nidificação seguro para ovoposição. Segundo Clark e Shutler (1999), as características da vegetação próximas ao ninho são de grande relevância para dificultar a localização dos ninhos pelos predadores, aumentando as suas chances de sobrevivência. Dessa forma, as particularidades da vegetação próximas ao ninho, como presença de espinhos nos galhos e densidade de vegetação atuam impactando na eficiência de forrageio dos potenciais predadores (FILLIATER; BREITWISCH; NEALEN, 1994).

Dessa forma, a maior predação em áreas campestres demonstrada no trabalho pode ser explicada devido a menor densidade de cobertura vegetal ao redor do ninho, deixando-os mais expostos a predadores e consequentemente aumentando a taxa de predação. Devido à ausência de dossel e cobertura para ocultar os ninhos, áreas campestres sofrem especialmente com predadores aves, que levam grande vantagem, já que são visualmente orientadas, principalmente durante seu voo e são tidos como os principais predadores de ninhos de outras aves (MENEZES; MARINI, 2017; FRANÇA et al., 2009).

A hipótese proposta de que ninhos em áreas florestais seriam menos predados é suportada por alguns trabalhos que observaram um efeito positivo entre uma maior cobertura vegetal ao redor dos ninhos e seu sucesso (COATES; DELEHANTY, 2008; DELONG et al., 1995). A maior densidade de material vegetal tende a prejudicar os predadores visualmente 
orientados, como as aves, mas não possui efeito sobre mamíferos e outros predadores especializados nesse tipo de condição ambiental com baixa visibilidade (BATÁRY et al., 2014).

A relação do efeito da estrutura da vegetação na sobrevivência dos ninhos é bem diversificada (WINTER; JOHNSON; SHAFFER, 2005), contendo espécies que demonstraram mais sobrevivência dos ninhos proveniente da ocultação dos ninhos pela estrutura da vegetação, como Watters et al. (2002). O autor diz que aves que selecionam locais com gramíneas ou arbustos altos e densos, obtiveram maior sucesso devido a cobertura vegetal, atuando como facilitador na ocultação do ninho e evitando alguns predadores aves, já que a gramínea ou arbustos podem atrapalhar na movimentação de predadores terrestres de menor porte e consequentemente dificultar a detecção e acessibilidade aos ninhos.

Outro fator que pode ter contribuído para uma menor predação em áreas florestais nos resultados encontrados pode ter sido a utilização de ninhos artificiais, gerando uma menor atração para os predadores mais comumente encontrados em áreas florestais, como as serpentes e mamíferos (THOMPSON; BURHANS, 2004). Deve-se levar em conta que um dos principais sentidos desse animais para forragear acaba sendo o olfato e os ninhos não possuem o odor natural e ruído dos filhotes e adultos (DJOMO NANA et al., 2015).

Aliado a isso, encontramos uma taxa de predação superior em ovos de plasticina contra ovos de codorna. A maior predação de ovos de plasticina pode estar associada a utilização de ovos de codorna no mesmo ninho, cuja a composição da casca é mais dura, e pequenos mamíferos não conseguem quebra-la. (RANGEN; CLARK; HOBSON, 2000).

Diversos predadores foram registrados em estudos envolvendo identificação de predação de ninhos, corroborando com nossos resultados (ALVAREZ; GALETTI, 2007). Segundo a literatura, ninhos situados em áreas campestres sofrem maior predação por predadores aves (DODONOV; PANECZKO; TELLES, 2017; RIBEIRO SILVA et al., 2018), em relação a mamíferos, confirmando o resultado encontrado. Enquanto em áreas florestais encontramos justamente o contrário, assim como na literatura (BOAG; REEBS; SCHROEDER, 1984), onde ninhos predados por mamíferos foram maioria em comparação com as aves.

Nossos resultados sobre a coloração dos ovos indicaram que existe relação entre a cor dos ovos com a chance de localização dos ninhos pelos predadores. A concepção de conspicuidade de ovos é relativa, levando em conta que nem sempre uma cor atrativa para nós será perceptível por potenciais predadores da área, como por exemplo as aves, que são os principais predadores que dependem da visão para forragear (CASTILLA et al., 2007). Já os 
mamíferos com hábitos noturnos, conseguem localizar os ninhos utilizando principalmente o olfato (RANGEN; CLARK; HOBSON, 2000). Enquanto as serpentes se guiam basicamente explorando pistas químicas (TEATHER, 1991).

Levando em consideração a densidade da vegetação e as aptidões de cada grupo de predadores, principalmente os predadores noturnos, a cor da casca dos ovos pode não ter efeito em ambientes florestais, onde a estrutura da vegetação e o substrato atuaria mascarando a coloração dos ovos. Já predadores diurnos podem ficar estimulados com ovos de coloração mais conspícua. Um estudo realizado com diversas aves da Amazônia associou a cor conspícua azul dos seus ovos com a coloração verde das folhagens e arbustos que recebiam diretamente a luz solar, fazendo com que o substrato possibilite um efeito de camuflagem nos ovos, tornando-os crípticos para alguns predadores e possivelmente conspícuo para outros (ONIKI, 1985).

O nível de exposição a luminosidade no conteúdo dos ninhos também pode favorecer a localização dos ovos pelos predadores ou impactar na refletância ou absorção de luz pela casca dos ovos, influenciando no resfriamento ou superaquecimento dos embriões (MAINWARING et al., 2014). Hanley et al. (2013), encontraram evidências demonstrando que a taxa de predação está associada a ao brilho da casca do ovo, sugerindo uma "hipótese da chantagem", na qual ele infere que as fêmeas colocam cascas de ovos coloridas para coagir os machos a fornecer cuidados adicionais durante a incubação para manter os ovos coloridos cobertos e diminuir a chance de predação.

Nossos resultados suportaram a expectativa de que ninhos alocados em alta densidade seriam mais predados. Gates e Gysel (1978) afirmam que o aumento da densidade de ninhos em um habitat reduzido pode aumentar consideravelmente a taxa de predação, e isso depende de como os predadores avaliam e reagem à heterogeneidade espacial e temporal ou em relação a abundância de recursos. A resposta depende diretamente do comportamento de forrageamento do animal. Em situações de alta concentração de ninhos próximos, se o predador encontrar alguns ninhos, o fator recompensa o fará investir mais tempo na busca. No caso de predadores grandes ou com elevada capacidade de locomoção, eles tendem a ter uma área de buscar maior, gerando uma taxa de predação maior na área (CARPIO; CASTROCARO; TORTOSA, 2016).

Adicionalmente, Elliot (1985) diz que aves sociais ou coloniais, que nidificam em grupos e possuem comportamentos de turba contra predadores, tendem a ter uma maior 
sobrevivência dos ninhos. Porém, espécies que são solitárias, como Volatinia jacarina, e possuem uma grande agregação devido aos seus territórios pequenos (ALMEIDA; MACEDO, 2001), geram uma densidade de ninhos grande, o que pode favorecer predadores. Vale complementar que o risco aumenta caso as aves realizam display, podendo sofrer uma maior predação por atrair atenção para a área, sinalizando para predadores que é uma área de potencial forrageio (CANDOLIN, 1997).

\section{CONSIDERAÇÕES FINAIS}

Tendo em vista as variáveis analisadas, observamos que a estrutura da vegetação, densidade de ninhos e coloração de ovos sugeriram influência na taxa de predação de ninhos. O efeito citado demonstrou que a cobertura vegetal pode ter grande papel atuando como obstáculo para a visualização dos ninhos, resultando em uma maior dificuldade dos predadores localizarem os ninhos, principalmente os visualmente orientados, como as aves, e que são considerados por alguns autores como os principais predadores de ninhos de outras aves.

O tema relacionado a influência da densidade de ninhos e coloração dos ovos na predação de ninhos é muito discutido por vários autores, trazendo resultados diferentes para perguntas semelhantes. De fato, uma maior demanda de estudos acaba sendo necessária para avaliar essas questões. Principalmente porque os predadores reagem diferentemente em certa conjuntura espaço-temporal, clima e sazonalidade, trazendo essa divergência de resultados na literatura.

Os efeitos de densidade de ninhos apontaram efeito significativo devido a maior agregação de ninhos em um espaço reduzido. Essa alta densidade de aves e ninhos pode alertar possíveis predadores sobre uma área com grande potencial de recursos, tornando essa área mais visada por eventuais predadores.

Em sequência, o efeito da coloração conspícua e críptica na taxa de predação dos ovos foi significante e pode estar relacionada com a densidade da vegetação, que pode atuar ocultando os ovos conspícuos de predadores de hábitos diurnos, que são visualmente orientados. Porém, os predadores noturnos utilizam de outros sentidos, que não a visão, como pistas químicas e auditivas. 
Trabalhos relacionados a identificação de predadores foram mais facilmente localizados em bases nacionais. Enquanto que estudos demonstram a relação da predação envolvendo densidade de ninhos e coloração de ovos é de grande maioria estrangeira, localizados principalmente no hemisfério norte, cuja biodiversidade acaba sendo, de certa forma, inferior à regiões neotropicais, e que, consequentemente, abriga uma riquíssima diversidade, tanto a avifauna quanto os predadores de ninhos. Os resultados apresentados podem contribuir para futuros projetos que busquem somar forças para compreender mais sobre fatores ecológicos envolvendo a dinâmica populacional das aves e seus fatores regulatórios, como a predação de ninhos. Adicionalmente, os resultados podem ajudar a estabelecer melhores estratégias de manejo de predadores com objetivo em otimizar o sucesso reprodutivo de aves ameaçadas.

\section{REFERÊNCIAS}

ALMEIDA, J. B.; MACEDO, R. H. Lek-Like Mating System of the Monogamous Blue-Black Grassquit. The Auk, v. 118, n. 2, p. 404-411, 2001.

ALVAREZ, A. D.; GALETTI, M. Predação de ninhos artificiais em uma ilha na Mata Atlântica: testando o local e o tipo de ovo. Revista Brasileira de Zoologia, v. 24, n. 4, p. 1011-1016, 2007.

BAASCH, D. M. et al. Nest-site selection by Interior Least Terns and Piping Plovers at managed, off-channel sites along the Central Platte River in Nebraska, USA. Journal of Field Ornithology, v. 88, n. 3, p. 236-249, 2017.

BATÁRY, P. et al. How do edge effect and tree species diversity change bird diversity and avian nest survival in Germany's largest deciduous forest? Forest Ecology and Management, v. 319, p. 44-50, 2014.

BOAG, D. A.; REEBS, S. G.; SCHROEDER, M. A. Egg Loss Among Spruce Grouse Inhabiting Lodgepole Pine Forests. Canadian Journal of Zoology, v. 62, n. 6, p. 1034-1037, 1984.

BRENNAN, P. L. R. Clutch predation in great tinamous Tinamus major and implications for the evolution of egg color. Journal of Avian Biology, v. 41, n. 4, p. 419-426, 2010.

CâMARA, P. E. A. S. Hepáticas e antóceros das matas de galeria da Reserva Ecológica do IBGE, RECOR, Distrito Federal, Brasil. Acta Botanica Brasilica, v. 22, n. 4, p. 1027-1035, 2008.

CANDOLIN, U. Predation risk affects courtship and attractiveness of competing threespine stickleback males. Behavioral Ecology and Sociobiology, v. 41, n. 2, p. 81-87, 1997.

CARDOSO DA SILVA, J. M.; BATES, J. M. Biogeographic Patterns and Conservation in the South American Cerrado: A Tropical Savanna Hotspot. BioScience, v. 52, n. 3, p. 225, 2002. 
CARPIO, A. J.; CASTRO-CARO, J. C.; TORTOSA, F. S. The Influence of Nest Density on Nest Predation in Olive Groves Depends on Habitat Features. Ardeola, v. 63, n. 2, p. 237-250, 2016 .

CARPIO, A. J.; CASTRO-CARO, J. C.; TORTOSA, F. S. The Influence of Nest Density on Nest Predation in Olive Groves Depends on Habitat Features. Ardeola, v. 63, n. 2, p. 237-250, 2016b.

CASTILLA, A. M. et al. Predation in ground-nesting birds: an experimental study using natural egg-color variation. Avian Conservation and Ecology, v. 2, n. 1, 2007.

CLARK, R. G.; SHUTLER, D. Avian Habitat Selection: Pattern from Process in Nest-Site Use by Ducks ? Ecology, v. 80, n. 1, p. 272-287, 1999.

COATES, P. S.; DELEHANTY, D. J. Effects of Environmental Factors on Incubation Patterns of Greater Sage-Grouse. The Condor, v. 110, n. 4, p. 627-638, 2008.

CONWAY, C. J.; MARTIN, T. E. Evolution of Passerine Incubation Behavior : Influence of Food, Temperature and Nest Predation. Evolution, v. 54, n. 2, p. 670-685, 2000.

DELONG, A. K. et al. Relationships between Vegetational Structure and Predation of Artificial Sage Grouse Nests. Journal of Wildlife Management, v. 59, n. 1, p. 88-92, 1995.

DJOMO NANA, E. et al. Relationship between Survival Rate of Avian Artificial Nests and Forest Vegetation Structure along a Tropical Altitudinal Gradient on Mount Cameroon. Biotropica, v. 47, n. 6, p. 758-764, 2015.

DODONOV, P.; PANECZKO, I. T.; TELLES, M. Edge, height and visibility effects on nest predation by birds and mammals in the Brazilian cerrado. Acta Oecologica, v. 83, p. 56-64, 2017.

ELLIOT, R. D. The exclusion of avian predators from aggregations of nesting lapwings (Vanellus vanellus). Animal Behaviour, v. 33, n. 1, p. 308-314, 1985.

ENDLER, J. A. A Predator's View of Animal Color Patterns. In: Evolutionary Biology. [s.l: s.n.]. p. 319-364.

FILLIATER, T. S.; BREITWISCH, R.; NEALEN, P. M. Predation on Northern-Cardinal Nests - Does Choice of Nest-Site Matter? Condor, v. 96, n. 3, p. 761-768, 1994.

FRANÇA, L. C.; MARINI, M. Â. Teste do efeito de borda na predação de ninhos naturais e artificiais no Cerrado. Zoologia (Curitiba, Impresso), v. 26, n. 2, p. 241-250, 2009.

FRANÇA, L. F. et al. Passeriformes: nest predators and prey in a Neotropical Savannah in Central Brazil. Zoologia, v. 26, n. 4, p. 799-802, 2009.

FU, Y. et al. Nest predators, nest-site selection and nest success of the Emei Shan Liocichla (Liocichla omeiensis), a vulnerable babbler endemic to southwestern China. Avian Research, v. 7, n. 1, p. 1-6, 2016.

FULTON, G. R. Native marsupials as egg predators of artificial ground-nests in Australian woodland. Australian Journal of Zoology, v. 65, n. 3, p. 196-199, 2017. 
GATES, J. E.; GYSEL, L. W. Avian Nest Dispersion and Fledging Success in Field-Forest Ecotones. Ecology, v. 59, n. 5, p. 871-883, 1978.

HAFTORN, S.; REINERTSEN, R. The effect of temperature and clutch size on the energetic cost of incubation in a free-living blue tit (Parus caeruleus). The Auk, v. 102, n. 3, p. 470-478, 1985.

HANLEY, D. et al. Eggshell conspicuousness in ground nesting birds: Do conspicuous eggshells signal nest location to conspecifics? Avian Biology Research, v. 6, n. 2, p. 147-156, 2013.

HANLEY, D.; CASSEY, P.; DOUCET, S. M. Parents, predators, parasites, and the evolution of eggshell colour in open nesting birds. Evolutionary Ecology, v. 27, n. 3, p. 593-617, 2013.

HUNTON, P. Research on eggshell structure and quality: an historical overview. Revista Brasileira de Ciência Avícola, v. 7, n. 2, p. 67-71, 2005.

JAMES, F. C.; WAMER, N. O. Relationships between Temperate Forest Bird Communities and Vegetation Structure. Ecological Society of America, v. 63, n. 1, p. 159-171, 1982.

JEPSON, W. A disappearing biome ? Reconsidering land-cover change in the Brazilian savanna. The Geographical Journal, v. 171, n. 2, p. 99-111, 2005.

JONER, D. C.; RIBEIRO, L. F. Perspectivas de projetos de pesquisa sobre predação de ninhos artificiais no bioma Cerrado. Natureza on line, v. 7, p. 74-79, 2009.

KLINK, C. A.; MACHADO, R. B. Conservation of the Brazilian Cerrado. Conservation Biology, v. 19, n. 3, p. 707-713, 2005.

LINDELL, C. Patterns of nest usurpation: when should species converge on nest niches? The Condor, v. 98, p. 464-473, 1996.

MAINWARING, M. C. et al. The design and function of birds' nests. Ecology and Evolution, v. 4, n. 20, p. 3909-3928, 2014.

MARINI, M. Â. et al. Biologia reprodutiva de Elaenia cristata (Aves: Tyrannidae) em cerrado do Brasil central. Neotropical Biology and Conservation, v. 4, n. 1, p. 2-12, 2009.

MENEZES, J. C. T.; MARINI, M. Â. Predators of bird nests in the Neotropics: a review. Journal of Field Ornithology, v. 88, n. 2, p. 99-114, 2017.

MURPHY, M. E. of avian eggs and tissues : Nutritional Amino acid compositions implications. Oikos, v. 25, n. 1, p. 27-38, 2010.

ONIKI, Y. Why robin eggs are blue and birds build nests: statistical tests for amazonian birds. Ornithological Monographs, n. 36, p. 536-545, 1985.

PADILHA, J. DO C. AVALIAÇÃO DA PREDAÇÃO DE OVOS EM NINHOS ARTIFICIAIS POR Callithrix spp. EM PARATY-RJ. Revista de Controle Biológico, v. 1, p. 11-16, 2009.

RANGEN, S. A.; CLARK, R. G.; HOBSON, K. A. Visual and olfactory attributes of artificial nests. The auk, v. 117, n. 1, p. 136-146, 2000.

RIBEIRO, J. F., \& WALTER, B. M. T. Fitofisionomias do bioma Cerrado. In: Cerrado : ambiente e flora. [s.l: s.n.]. p. 556. 
RIBEIRO, J. F. et al. Os principais tipos fitosionômicos da região dos Cerrados.Boletim de Pesquisa EMBRAPA/CPAC, 1983.

RIBEIRO SILVA, L. et al. Testing camera traps as a potential tool for detecting nest predation of birds in a tropical rainforest environment. Zoologia, n. 35, p. 1-8, 2018.

RICKLEFS, R. E. An Analysis of $f$ Nesting Mortality in Birds. Smithsonian contributions to zoology, n. 9, p. 48, 1969.

RODRIGUEZ, M. N. Efeito Do Tamanho Do Fragmento Na Taxa De Predação Em Ninhos Artificiais De Aves No Parque Estadual De Vila Velha, Ponta Grossa, Paraná. [s.I: s.n.].

SCARIOT, A.; SOUSA-SILVA, J. C.; FELFILI, J. M. Cerrado: Ecologogia, Biodiversidade e Conservação. [s.l: s.n.].

SOLÍS, J. C.; LOPE, F. DE. Nest and egg crypsis in the ground-nesting stone curlew Burhinus oedicnemus. Journal of Avian Biology, v. 26, n. 2, p. 135-138, 1995.

STEELE, M. A. Tamiasciurus hudsonicus. Mammalian Species, n. 586, p. 1-9, 1998.

STEVENS, M. et al. Improvement of individual camouflage through background choice in ground-nesting birds. Nature Ecology and Evolution, v. 1, n. 9, p. 1325-1333, 2017.

STODDARD, M. C.; MARSHALL, K. L. A.; KILNER, R. M. Imperfectly camouflaged avian eggs: Artefact or adaptation? Avian Biology Research, v. 4, n. 4, p. 196-213, 2011.

STUTCHBURY, B. J. M.; MORTON, E. S. Behavioral ecology of tropical birds. San Diego: Academic Press, 2001.

TEATHER, K. L. The relative importance of visual and chemical cues for foraging in newborn Blue-Striped Garter Snakes (Thamnophis sirtalis similis). Behaviour, v. 117, n. 3-4, p. 255-261, 1991.

THOMPSON, F. R.; BURHANS, D. E. Differences in predators of artificial and real songbird nests: Evidence of bias in artificial nest studies. Conservation Biology, v. 18, n. 2, p. 373-380, 2004.

WATTERS, M. E. et al. The effect of vegetation structure on predation of artificial Greater SageGrouse nests. Ecoscience, v. 9, n. August, p. 314-319, 2002.

WEIDINGER, K. Interactive effects of concealment, parental behaviour and predators on the survival of open passerine nests. Journal of Animal Ecology, v. 71, n. 3, p. 424-437, 2002.

WINTER, M.; JOHNSON, D. H.; SHAFFER, J. A. Variability in Vegetation Effects on Density and Nesting Success of Grassland Birds. Journal of Wildlife Management, v. 69, n. 1, p. 185-197, 2005.

ZELDITCH, M. L. et al. Modularity of the rodent mandible: Integrating bones, muscles, and teeth. Evolution and Development, v. 10, n. 6, p. 756-768, 2008. 